\title{
Drying kinetics of passion fruit peel for tea products
}

\author{
Chatsuda Sittipa ${ }^{1 *}$, Siva Achariyaviriya ${ }^{1 \dagger}$, Aree Achariyaviriya ${ }^{1}$, and James C. Moran ${ }^{1}$ \\ ${ }^{1}$ Chiang Mai University, Department of Mechanical Engineering, 50200 Chiang Mai, Thailand
}

\begin{abstract}
An important step in the development of passion fruit tea products is the drying procedure. This procedure uses a lot of energy. The optimization of drying needs knowledge of the drying kinetics. This paper focuses the development of drying kinetics for passion fruit peel. The experiments were conducted utilizing a thin layer dryer with drying air temperatures in the range of $45^{\circ} \mathrm{C}$ to $65^{\circ} \mathrm{C}$ The drying air velocity was constant at $1 \mathrm{~m} / \mathrm{s}$. The passion fruit peel were dried from their initial moisture content of $559 \pm 16 \% \mathrm{db}$ to a final moisture content of $50 \pm 1 \% \mathrm{db}$. The models for the kinetic drying proposed by the authors are the Newton model, Page model and the Logarithmic model. The parameters for the drying kinetic models were found by curve fitting the experimental data using non-linear regression. The criteria for evaluating the models were the coefficient of determination $\left(R^{2}\right)$, a root mean square error $(R M S E)$ and a reduced chisquare $\left(\chi^{2}\right)$. It was found that the drying kinetic model for passion fruit peel which gave the best fit was the Page model. This drying kinetic model can be applied to find optimum drying conditions.
\end{abstract}

\section{Introduction}

Passion fruit is genus Passiflora L. The passion fruit comes from tropical America and is cultivated in regions where the climate is tropical or subtropical [1]. Thailand has a climate that resembles a tropical climate. Passion fruit is a popular fruit crop. It is a plant that can be grown throughout the year. It can yield large quantities during the months of August and February. A single passion fruit weighs approximately $170 \mathrm{~g}$, of which $53 \%$ is peel, $20.9 \%$ is seed and $26 \%$ is pulp [2]. In general, seed and pulp are consumed fresh and processed into juice. Therefore, this leaves over half the passion fruit as waste [3]. However, the waste is usable, as it is rich in bioactive compounds, such as vitamins $\mathrm{C}$, minerals and polyphenolic compounds. These have a high antioxidant capacity and contain dietary fiber [4]. It can also help prevent cancer, heart disease and diabetes and helps in the digestive system [5]. The idea is to process the passion fruit peel for tea.

\footnotetext{
* Corresponding author: woontrw@gmail.com

$\dagger$ Corresponding author: siva@dome.eng.cmu.ac.th
} 


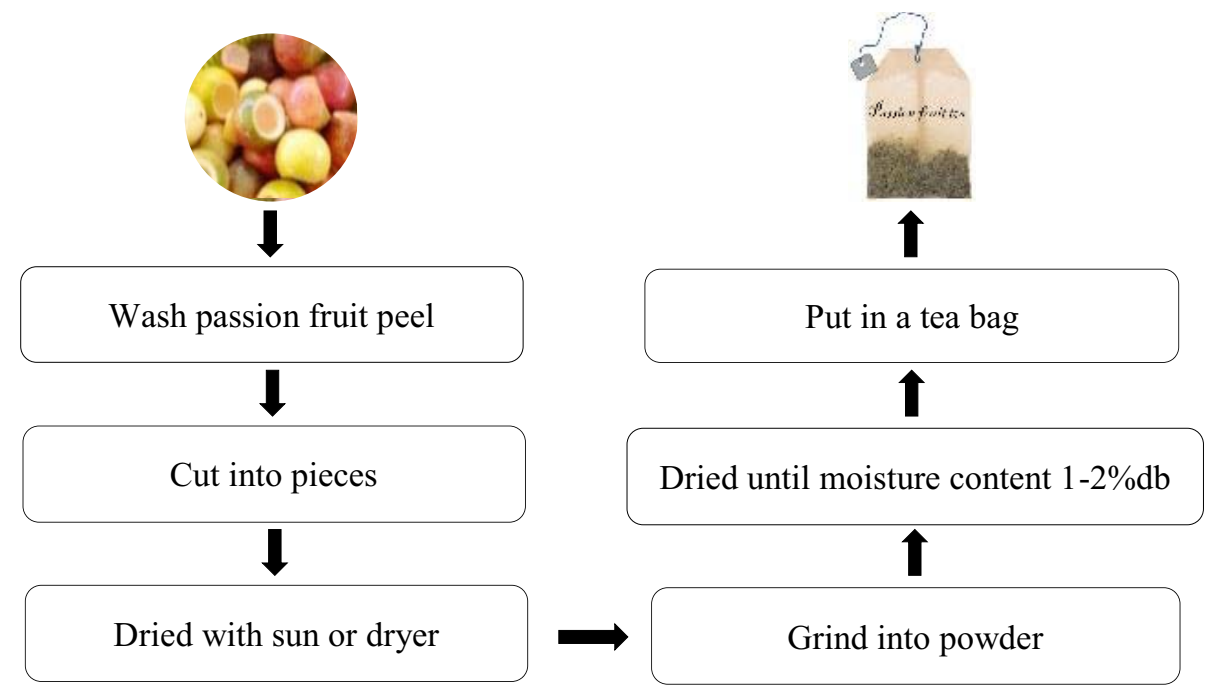

Fig. 1. Schematic diagram of procedure for passion fruit tea products.

Passion fruit peel for tea is typically processed as shown in Figure 1. The important step in tea processing is drying passion fruit peel. Drying with hot air is the method used. From an energy viewpoint, it is necessary to find the optimal drying conditions and to know the production basics. Bezerra et al. [5] studied passion fruit peel drying kinetics. The initial moisture content of the passion fruit peel was $86.4 \pm 1.3 \% \mathrm{wb}$ and the final moisture content was $8.9 \pm 1.4 \% \mathrm{wb}$. The drying air temperatures were in the range of $50-70^{\circ} \mathrm{C}$. The Dincer and Dost [6] drying model was the optimal model for passion fruit peel. Literature of drying kinetics models, such as, Kenenia et al. [7] used the model of Avhad and Marchetti [8] for developing the drying kinetic model of jatropha curcass. Achariyaviriya et al. [9] studied the drying kinetics of persimmon fruits, Kunsathein and Achariyaviriya [10] took a diffusion approach model for sliced banana. Chailungka and Assawarachan [11] relied on theoretical and empirical models for spirogyra sp. Mongkolkerd and Achariyaviriya [12] developed drying kinetics models for okra. There is no research on the drying of passion fruit peel for tea products. The aim of this work is to find a suitable model for the drying kinetics of passion fruit peel. This drying kinetics equation can be applied to predict the most energy efficient drying process.

\section{Materials and methods}

\subsection{Raw material}

Passion fruit used in this study was purchased from the Royal project in Chiang Mai Province, Thailand. The diameter of passion fruit were in the range of 5.0-5.8 cm. Weight per fruit was $80 \pm 2 \mathrm{~g}$. Passion fruit were cleaned and cut into 4 pieces, and then the flesh, the core, the pulp and seeds were removed. The initial moisture content ranged from 543 to $575 \% \mathrm{db}$.

\subsection{Moisture content determination}

The selected passion fruit peels (initial mass $100 \mathrm{~g}$ ) were put into the hot air oven. The air temperature in the oven was $103^{\circ} \mathrm{C}$. They were dried in the oven about $72 \mathrm{~h}$. Then, the passion 
fruit peels were weighed to get the dry bone mass using a digital balance (accuracy $= \pm 0.001$ g). The moisture content can be calculated by Equation (1).

$$
M=\frac{m-m_{b}}{m_{b}}
$$

Where, " $m$ " is the mass of the initial passion fruit peels, " $m_{b}$ " is the mass of the dry bone passion fruit peels, and " $M$ " is the moisture content of passion fruit peels.

\subsection{Experimental setup and procedure}

In this research, a thin layer dryer was used. The experiments were performed in the drying laboratory of the Mechanical Engineering Department of Chiang Mai University as shown in Figure 2 . The air velocity was constant at $1 \mathrm{~m} / \mathrm{s}$ inside a drying chamber of diameter $20 \mathrm{~cm}$. The experiments were conducted at hot air temperature of $45{ }^{\circ} \mathrm{C}, 55{ }^{\circ} \mathrm{C}$ and $65^{\circ} \mathrm{C}$. Approximately $300 \pm 5 \mathrm{~g}$ of passion fruit peel was prepared in each experiment. During the drying process, the drying temperature, product temperature, and product weight were recorded until their final steady state weight. A total of nine experiments were carried out in this study.

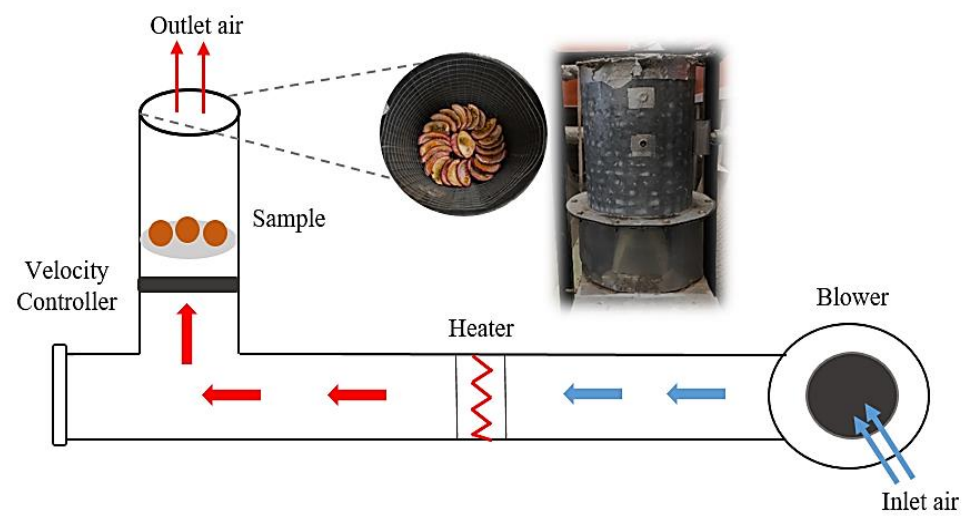

Fig. 2. Schematic diagram of the thin layer dryer.

\subsection{Mathematical modeling}

The drying kinetics equations for passion fruit peel were based on three models, namely, the Newton model [13], Page model [14] and Logarithmic model [15]. Each model is shown in Equations (2) to (4).

$$
\begin{array}{ll}
\text { Newton Model: } & M R=\exp (-k t) \\
\text { Page Model: } & M R=\exp \left(-p t^{n}\right) \\
\text { Logarithmic Model: } & M R=a \exp (-b t)+c
\end{array}
$$

Where, "MR" is the ratio between moisture content and the initial moisture and " $k, p, n$, $a, b$ and $c$ " are the parameters. The parameter (or parameters) in each model was calculated by fitting the experimental data to each drying kinetics model using least square method. 


\subsection{Statistical analysis}

A coefficient of determination $\left(R^{2}\right)$ [16], a root mean square error (RMSE) [17] and a reduced chi-square $\left(\chi^{2}\right)$ [17] were used as the criteria for model selection. They are calculated as follows:

$$
\begin{gathered}
R^{2}=\frac{\sum_{i=1}^{N}\left(M R_{p r e, i}-\overline{M R}_{e x}\right)^{2}}{\sum_{i=1}^{N}\left(M R_{e x, i}-\overline{M R}_{e x}\right)^{2}} \\
R M S E=\left[\frac{1}{N} \sum_{i=1}^{N}\left(M R_{p r e, i}-M R_{e x, i}\right)^{2}\right]^{0.5} \\
\chi^{2}=\frac{\sum_{i=1}^{N}\left(M R_{e x, i}-M R_{p r e, i}\right)^{2}}{N-z}
\end{gathered}
$$

$\overline{M R}_{e x}$ is the average experimental moisture ratio, $M R_{e x, i}$ is the experimental moisture ratio, $M R_{p r e, i}$ is the predicted moisture ratio, $N$ is the number of observations, and $z$ is the number of constants.

\section{Results and discussion}

The passion fruit peel began with an initial moisture content of $559 \pm 16 \% \mathrm{db}$ and finished at a final moisture content of $50 \pm 1 \% \mathrm{db}$. Figure 3, illustrates the relationship between moisture content and drying time at drying air temperatures of $45^{\circ} \mathrm{C}, 55^{\circ} \mathrm{C}$ and $65^{\circ} \mathrm{C}$. Drying time was observed to decrease with increasing air temperature. High air temperatures resulted in moisture decreasing more rapidly compared with lower air temperatures. The specific drying rate at drying air temperatures of $45^{\circ} \mathrm{C}, 55^{\circ} \mathrm{C}$ and $65^{\circ} \mathrm{C}$ was in the range of $0.23-0.25,0.46-$ 0.48 and $1.28-1.62 \mathrm{~kg}_{\text {water }} / \mathrm{kg}_{\text {dry product }} \mathrm{h}$, respectively. The results are consistent with drying of other fruits where the drying rate increases with increasing air temperatures. Additionally, these results do not stabilize to a constant drying rate, they only have a falling drying rate.

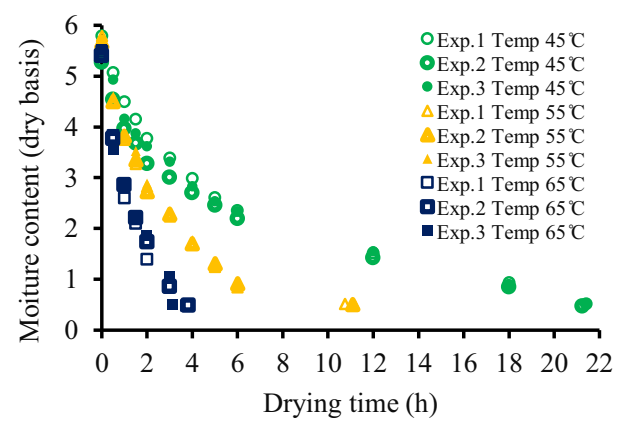

Fig. 3. Results of the relationship between moisture content and drying time at various drying air temperatures. 
The moisture ratio and drying time were fitted to the following drying kinetic models: Newton, Page and Logarithmic. The curves were fitted using non-linear regression. The model parameters of each experiment are shown in Table 1. It is found from Table 1 that, the parameters of each experiment at the same drying air temperature are very close. The parameters of each model increase with increasing drying air temperature.

A coefficient of determination $\left(R^{2}\right)$, a root mean square error (RMSE), and a reduced chisquare $\left(\chi^{2}\right)$ were used to measure the effectiveness of these models. The analysis is shown in Table 2. The optimal model should have a high value of the coefficient of determination $\left(R^{2}\right)$, a low value of the root mean square error (RMSE), and of the reduced chi-square $\left(\chi^{2}\right.$ ). The Newton, Page and Logarithmic models had an average coefficient of determination $\left(R^{2}\right)$ of $0.966,0.993$ and 0.989 . They gave an average root mean square error (RMSE) of $0.0487,0.0233$ and 0.0354 , an average reduced chi-square $\left(\chi^{2}\right)$ of $0.0030,0.0008$ and 0.0021 , respectively. It was found that the Page model provided the lowest root mean square error $(R M S E)$ and the lowest reduced chi-square $\left(\chi^{2}\right)$. The Page model also gave the highest value for the coefficient of determination $\left(R^{2}\right)$.

Table 1. Parameters of drying kinetic models for passion fruit peel.

\begin{tabular}{|c|c|c|c|c|c|c|c|c|c|c|}
\hline \multirow{3}{*}{ Model } & \multirow{3}{*}{$\begin{array}{l}\text { Paramet } \\
\text { er }\end{array}$} & \multicolumn{9}{|c|}{ Value of parameter } \\
\hline & & \multicolumn{3}{|c|}{ at $45^{\circ} \mathrm{C}$} & \multicolumn{3}{|c|}{ at $55^{\circ} \mathrm{C}$} & \multicolumn{3}{|c|}{ at $65^{\circ} \mathrm{C}$} \\
\hline & & Exp.1 & Exp.2 & Exp.3 & Exp.1 & Exp.2 & Exp.3 & Exp.1 & Exp.2 & Exp.3 \\
\hline \multirow{2}{*}{ Newton } & \multirow{2}{*}{$k$} & 0.15 & 0.15 & 0.16 & 0.33 & 0.32 & 0.29 & 0.67 & 0.61 & 0.63 \\
\hline & & 8 & 6 & 3 & 9 & 4 & 6 & 7 & 3 & 3 \\
\hline \multirow{4}{*}{ Page } & \multirow{2}{*}{$p$} & 0.25 & 0.24 & 0.27 & 0.42 & 0.39 & 0.36 & 0.70 & 0.63 & 0.68 \\
\hline & & 2 & 1 & 5 & 0 & 6 & 7 & 1 & 6 & 4 \\
\hline & \multirow[b]{2}{*}{$n$} & 0.70 & 0.71 & 0.66 & 0.78 & 0.80 & 0.80 & 0.91 & 0.92 & 0.84 \\
\hline & & 1 & 5 & 0 & 5 & 5 & 3 & 7 & 7 & 5 \\
\hline \multirow{6}{*}{ Logarithmic } & \multirow{2}{*}{$a$} & 0.82 & 0.82 & 0.79 & 0.87 & 0.88 & 0.88 & 0.95 & 0.97 & 0.94 \\
\hline & & 0 & 6 & 7 & 9 & 6 & 8 & 4 & 9 & 6 \\
\hline & \multirow{2}{*}{$b$} & 0.19 & 0.19 & 0.19 & 0.38 & 0.37 & 0.32 & 0.73 & 0.60 & 0.63 \\
\hline & & 1 & 1 & 3 & 9 & 5 & 8 & 9 & 7 & 8 \\
\hline & \multirow[b]{2}{*}{$c$} & 0.12 & 0.12 & 0.13 & 0.08 & 0.08 & 0.07 & 0.04 & 0.00 & 0.02 \\
\hline & & 7 & 9 & 3 & 4 & 5 & 4 & 1 & 4 & 2 \\
\hline
\end{tabular}

Table 2. Effectiveness of the drying kinetic models for passion fruit peel.

\begin{tabular}{|l|c|ccc|ccc|ccc|}
\hline \multirow{3}{*}{ Model } & \multirow{2}{*}{$\begin{array}{c}\text { Temp } \\
{ }^{\circ} \mathrm{C}\end{array}$} & \multicolumn{4}{|c|}{$R^{2}$} & \multicolumn{4}{|c|}{$R M S E$} & \multicolumn{3}{c|}{$\chi^{2}$} \\
\cline { 3 - 11 } & & Exp.1 & Exp.2 & Exp.3 & Exp.1 & Exp.2 & Exp.3 & Exp.1 & Exp.2 & Exp.3 \\
\hline \multirow{4}{*}{ Newton } & 45 & 0.945 & 0.934 & 0.919 & 0.0634 & 0.0739 & 0.0754 & 0.0044 & 0.0060 & 0.0062 \\
& 55 & 0.977 & 0.981 & 0.973 & 0.0445 & 0.0384 & 0.0493 & 0.0022 & 0.0016 & 0.0027 \\
& 65 & 0.996 & 0.996 & 0.973 & 0.0225 & 0.0246 & 0.0462 & 0.0006 & 0.0007 & 0.0025 \\
\hline \multirow{4}{*}{ Page } & 45 & 0.998 & 0.985 & 0.995 & 0.0136 & 0.0203 & 0.0234 & 0.0002 & 0.0005 & 0.0007 \\
& 55 & 0.997 & 0.997 & 0.990 & 0.0171 & 0.0159 & 0.0381 & 0.0004 & 0.0003 & 0.0018 \\
& 65 & 0.998 & 0.997 & 0.981 & 0.0171 & 0.0242 & 0.0398 & 0.0004 & 0.0008 & 0.0022 \\
\hline \multirow{4}{*}{ Logarithmic c } & 45 & 0.997 & 0.975 & 0.976 & 0.0396 & 0.0501 & 0.0527 & 0.0021 & 0.0034 & 0.0037 \\
& 55 & 0.999 & 0.995 & 0.985 & 0.0183 & 0.0228 & 0.0498 & 0.0005 & 0.0007 & 0.0035 \\
& 65 & 0.998 & 0.996 & 0.977 & 0.0239 & 0.0176 & 0.0437 & 0.0010 & 0.0005 & 0.0033 \\
\hline
\end{tabular}


In Table 2, the parameters in each model were fitted to the exponential equation as a function of drying air temperature. They can be expressed as follows:

Newton Model:

$$
\begin{array}{ll}
\text { Newton Model: } & k=0.006914 \exp (0.06967 T) \\
\text { Page Model: } & p=0.0284 \exp (0.0484 T) \\
& n=0.3884 \exp (0.0129 T) \\
\text { Logarithmic Model: } & a=0.5628 \exp (0.0082 T) \\
b & =0.0120 \exp (0.0617 T) \\
c & =19.258 \exp (-0.1067 T)
\end{array}
$$$$
\text { Logarithmic Model: } \quad a=0.5628 \exp (0.0082 T)
$$

Figure 4 to Figure 6 show the predicted moisture ratio of various models at air temperatures of $45^{\circ} \mathrm{C}, 55^{\circ} \mathrm{C}$ and $65^{\circ} \mathrm{C}$, respectively. The predicted moisture ratio of the Page model were closer to the experimental results than the other models. This was true for all air temperatures. The Page model was also the most effective. However, the Newton and Page models were as close as the Page model at high drying air temperature as shown in Figure 6.

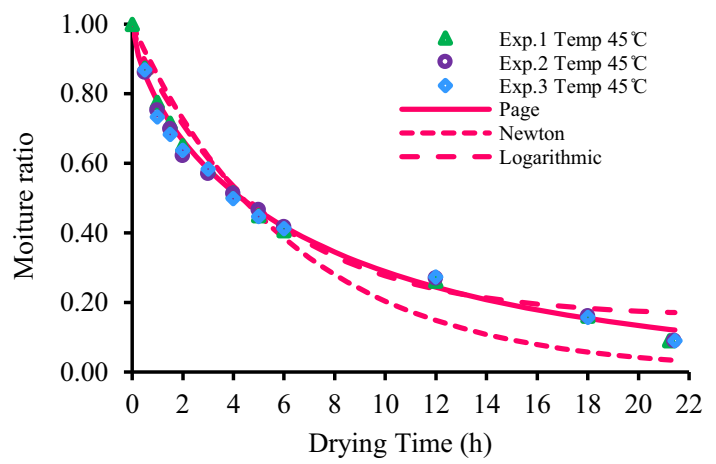

Fig. 4. Experimental moisture ratios compared with predicted moisture ratios of various models at drying air temperature of $45^{\circ} \mathrm{C}$.

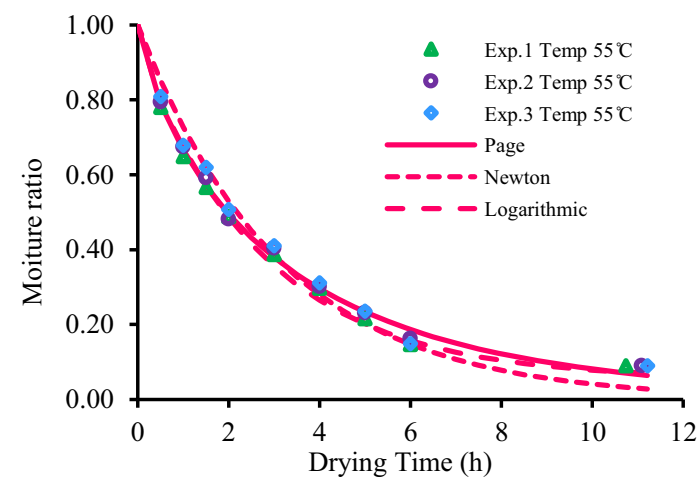

Fig. 5. Experimental moisture ratio compared with predicted moisture ratio of various models at drying air temperature of $55^{\circ} \mathrm{C}$. 


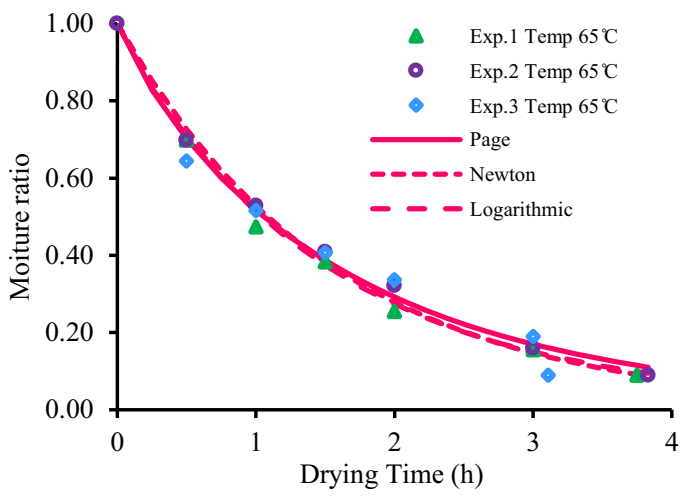

Fig. 6. Experimental moisture ratio compared with predicted moisture ratio of various models at drying air temperature of $65^{\circ} \mathrm{C}$.

Figure 7 shows that the moisture ratio calculated from the Page model compares with the experimental moisture ratios at various drying air temperatures. It was found that the results calculated from the Page model tracked the experimental results best at all drying air temperatures. This model also gave the lowest of $\chi^{2}$ and the lowest of RMSE. Moreover, this model has the highest value for $R^{2}$. Therefore, the Page model was found to be the most accurate for predicting drying rates of passion fruit peel. Similar results were obtained by other reserchers.

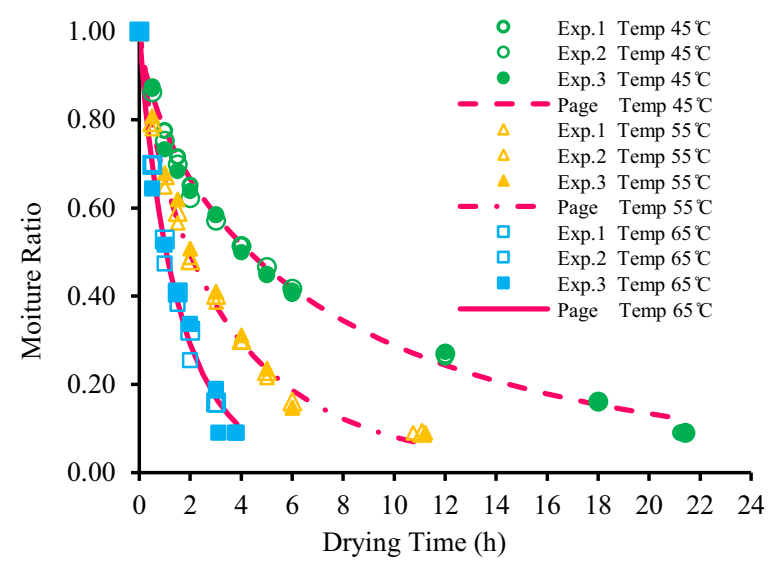

Fig. 7. Predicted moisture ratios of Page model compared with experimental moisture ratios at various drying air temperatures.

\section{Conclusion}

The results of this study indicate that the Page model can be used with reasonable accuracy and confidence to calculate the moisture content of passion fruit peels during drying. However, the model should only be used for air temperatures between $45^{\circ} \mathrm{C}$ to $65^{\circ} \mathrm{C}$ in order to ensure a precise value for the moisture content. This drying kinetic model could be useful in designing a drying process and to determine the optimal drying conditions. 
The authors would like to thank NHK-SPRING (Thailand) Co., Ltd. for research funding and cultivator in Mae Rim District, Chiang Mai Province, Thailand for facilitating the compilation of research results.

\section{References}

1. K. Kishore, K.A. Pathak, R. Shuklar, R. Bharali, J Food Sci Tech. 48, 484-488 (2011)

2. Y. Duarte, A. Chaux, N. Lopez, E. Largo, C. Ramirez, H. Nunez, R. Simpson, O. Vega, J Food Process Eng. 40, 1782-1791 (2016)

3. T.A. Duarte, V. Calado, C.W.P. Carvalho, Food Res Int. 49, 588-595 (2012)

4. F.T. Macagnan, L.R.d. Santos, B.S. Roberto, F.A.d. Moura, M. Bizzani, L.P.d. Silva, Bio Car Die Fib. 6, 1-6 (2015)

5. C.V. Bezerra, L.H.M.d. Silva, D.F. Correa, A.M.C. Rodrigues, Int J Heat Mass Tran. 85, 750-775 (2015)

6. I. Dincer, S. Dost, Dry Tech Int J. 13, 425-435 (1995)

7. Y.G Kenenia, A.K.T. Hvoslef-Eide, J.M. Marchetti, Ind Crop Prod. 132, 12-20 (2019)

8. M.R. Avhad, J.M. Marchetti, Ind Crop Prod. 91, 76-87 (2016)

9. S. Achariyaviriya, A. Achariyaviriya, T. Ketwichitchai, RMUTT. 2, 151-162 (2019)

10. N. Kunsathein, A. Achariyaviriya, Effect of temperature velocity and relative humidity of hot air on sliced banana drying, in Proceedings of the Ninth Conference on Heat and Mass Transfer, 86-90. Chiangmai University. 11-12 March 2010, Prachuap Khiri Khan Province, Thailand. (2019)

11. N. Chailungka, R. Assawarachan, J Res Dev. 26, 87-97 (2015)

12. K. Mongkolkerd, S. Achariyaviriya, J Interdiscipl Nets. 2, 19-25 (2013)

13. J.R. O'Callaghan, D.J. Menzies, P.H. Bailey, J Agr Eng Res, 16, 223-244 (1971)

14. G.E. Page, Unpublished M.S, Thesis, Purdue University, Indiena, 1-13 (1949)

15. O. Yaldiz, C. Ertekin, H.I. Uzun, Int J Energy, 26, 457-465 (2001)

16. T. M. Lin, T. D. Durance, C. H. Scaman, Food Res Int, 31, 111-117 (1998)

17. P.N. Sarsavadia, R.L. Sawhney, D.R. Pangavhane, S.P. Singh, J Food Eng, 40, 219$226(1999)$ 